\title{
Compliance or Complicity?
}

\section{A Response to Elizabeth Mowat \& Brent Davis}

\section{JEAN-FRANÇOIS MAHEUX}

University of Victoria (Canada)

\author{
Is not Mowat and Davis' paper \\ Somehow stressing compliance \\ Rather than complicity \\ In and through mathematics? \\ Looking through a rear window \\ Pondering on the stuff I find \\ I dive into deep waters \\ Wanting to knit complicities in and through mathematics \\ And, as an educator, \\ Speak up to my ethical responsibility \\ Through this response
}

\section{Rear Window}

Mowat and Davis' feature paper got me into a lot of thinking.

How much do we lose when we create models and theories?

What do we get in return?

And most importantly: Why do we do this? 
I am particularly surprised, if not worried

About the epistemological inflection

Given here, in the association of

Embodied mathematics and network theory

Is mathematics education still about

Getting the students to get it right?

Providing students with "chosen carefully" metaphors (p. 25)

(worked out from the discipline's conceptual epistemology)

To prevent "failure" in understanding? (p. 23)

Are we not, in doing this,

Stressing compliance?

Commitment to specified standards,

Conformity in filling up (the Latin complere)

Students' expected conceptual networks?

I am reminded of Reiss (1982)

When he notes that Western thought

Obsessively attempts to "explain the world, so as to conquer and transform it" (p. 21).

But what? Isn't that what science is all about?

Is there anything else we could be looking for?

Anything else we could be striving for?

\section{The Stuff We Find}

We find all kinds of stuff over the Internet

I was browsing Youtube

Sure to find a piece of video showing students doing some mathematics

Look at what I found

www.youtube.com/watch?v=Rp38JjygZH8

Four third-grade students are working on a task

They have to draw a segment $3 \mathrm{~cm}$ shorter than a given $8 \mathrm{~cm}$ segment

On the desk: Sheets of paper, and a ruler

That Pedro manipulates

There is a real beauty

In how those children are doing math together

Perceivable joy, passion, excitement

Please, look at it once again: 
The students are arguing: "It's 5!", "It's 6!"

Pedro insists on 5, and someone asks "Why?"

Pedro returns the question:

Pedro: Why, why do you think it's 6 ?

Gatto: Well because you have to count the 8 , and you have to ... which ever

Kim: Gatto, when you count the 8 it doesn't move.

Now there is a lot of fuss,

Voices overlapping, hands pointing, reaching.

Ben says something about " 9 "

Pedro: But the 8 does not count.

Kim: Why not?

Pedro: So it's 1, 2, 3. 5 plus 3 is 8 . Take 3 away from 8 , it's 5 .

Gatto: But it's almost to the 9!

Pedro: Take this away, which is 1,2 , that's 3 ! (counting on his ruler).

\section{In Deep Waters}

Lets get back to Mowat and Davis now.

They want to understand the nature of mathematics as a system of ideas

They argue that the system structure they outline

Based on Lakoff and Núñez's (2000) idea of embodied metaphor

Represents both mathematical understanding at the level of an individual

And mathematical knowledge as a discipline

These systems, they suggest

Are complex networks of sub-networks

Of sub-networks of sub-networks, and so on

And as such present features like a "scale-free topology"

Which improves the networks' robustness

Or decreases dependence over specific concepts or conceptual domains

From my perspective, a number of points demand some deep rethinking Why are "subjective understandings" viewed

As embedded in the system of formal mathematics (p. 7).

And not the other way around?

After all, is not mathematics only part of what Pedro and the others

Are experiencing in that conversation?

It also seems to me that many have argued

Against the "scaffolding" view of learning

Moving "from concrete and familiar domains ... to abstract concepts" (p. 16).

What of the movement from the abstract to the concrete? 
After all, did not Pedro use abstract arithmetic operations and equivalences To solve and explain a concrete measurement problem?

Similarly, I am reminded of a body of work explaining the drawbacks Of thinking in terms of individuals holding "conceptions" (p. 22, 26), Of which language and gesture are "simply surface manifestations" (p. 12). After all, can any of us observe Pedro's conceptions (of what?), And neglect that all he does is visibly done with and for the others?

But what more importantly takes my attention Is what Mowat and Davis find in their model, Their "useful interpretation or analogy" (p. 9), To be implications for education

Why this will to "orient instruction" (p. 25) Using metaphors to build stronger networks? An aim for "usefulness" that resonates so much With the will to explain, conquer and transform. A means to avoid breakdowns and collapses, And somehow deprive mathematical activity Of the agonistic dimension That also gives it life, and humanity.

“It's 5!", “It's 6!"

"But the 8 does not count."

"But it's almost to the 9!"

I am worried by a picture of education

Where all will go smoothly

In some sort of a Brave New World.

Where all the mechanisms are in place

To ensure discipline,

Compliance with the discipline.

Using metaphors to fit a certain logic, "understanding the structure of mathematics and, in consequence, informing pedagogy" (p. 2).

Instead of using metaphors to break with this logic And think about mathematics education differently. 


\section{Knitting Complicities}

As I sit back, thinking about Mowat and Davis' paper, And look at the conversation between Pedro, Gatto, Kim and Ben, I am surprised.

Where is the pleasure?

Where is the magic of children arguing?

Of Pedro asking "why do you think it's 6",

Of Gatto telling him that she "counts the 8",

Of Kim answering that you don't "move" at the starting point.

Where is the creative, responsive, human face of mathematics,

And mathematical activity?

It was some 15 years ago,

Davis himself was among those pioneering in mathematics education

Maturana \& Varela's (1998) enactivist approach.

In a short, inspiring paper, Davis (1995) then noted

That the question of "What is mathematics?"

Unfortunately tends to be answered in terms of knowing subjects or known objects. Resulting in a drive for efficiency in students' knowledge acquisition.

Exploring what an enactivist approach calls for, he then wrote:

The critical task seems to be not so much determining the nature of mathematics, for in posing the question in those terms, there is an implication that we can somehow consider the body of knowledge as determinable, fixable, and separable from ourselves-as though we could somehow step outside our mathematics. An enactivist turn on the question of knowledge would be to ask how we are knitted together in this particular body. How does the discipline contribute to our perceptions and define our actions? How does the subject matter help to shape the responsive world that we perceive and within which we act? (p. 2, my emphasis).

When I think and look at Pedro, Gatto, Kim and Ben, It is not the conceptual metaphors they embody that interests me.

I want to better appreciate how mathematical activity knits them, and us, together. How do we coexist in and through mathematical activity?

I can, of course, think in terms of metaphors,

I can discuss about measurements and the ruler,

About the association of counting and moving,

And map out the various ways in which Pedro

Talks about differences with additions and subtractions.

And so on. 
I can also make assumptions as to what stimuli

Triggered, in the children, the "nodes" associated to the numbers

And conjecture about what nodes are not activated...

But how does this help me considering

How mathematical activity weaves us together?

And fosters complicity, rather than compliance?

This seldom resonates with my enactive research approach,

In which complicity (being implicated with/in)

Moves me, as a researcher,

From trying to design and manage systems and structures

Towards an inquiry of dynamic engagement,

Of participation,

In a complex and forever emerging world.

Creating conditions for it to regenerate itself,

To flourish (Haskell, Linds \& Ippolito, 2002).

\section{As an Educator}

I am amazed by the complex coordination of actions between the four students.

I can immerse myself in that world of action.

As an educator, I can engage from that angle in bringing forth

A mathematical perspective.

I can appreciate the choreography of co-existence

That emerges when a student says " 5 " and another answers " 6 ".

When Pedro, by asking "why",

Gets Gatto to explain how she counts.

Which leads Kim to comment on that procedure,

Moving the conversation in that direction.

But I can also see myself participating in that bringing forth

Knitting, weaving, lacing, braiding

Cultivating complicities.

It is not by accident that Davis finds interest in cognitive structures.

Mathematical cognition, from an enactivist perspective,

Is actually conceived as

"an activity fully determined by a person's structure" (Kieren, 1995, p. 7).

And were I a cognitive scientist studying the nervous system,

A biologist like Maturana or Varela,

I would probably be interested in those structures.

What they might be, or might be like.

But as an educator, it is not what interests me. 
And I am not helpless.

Still following enactivism, one can see that

Those structures not only emerge, but always co-emerge.

They are something "in which [a person] brings forth

a world of mathematical significance

with others" (Kieren, 1995, p. 2).

I am overjoyed to see how

Mathematics is something these four students do with and for one another.

To see it as a way to coordinate themselves

In the common experience of the line, the ruler, the question.

In the togetherness of making mathematical observations.

What I need, as an educator is not simply a model of

Mathematics as a discipline or as what might be going on in students' head.

And especially not a model of that becomes a model for,

The shaping of those fugitive structures!

What I need, and begin to find in enactivism,

Is a way of thinking, and talking, that helps me see and foster

Students and teachers actions

As "complicit in the learning of others" (Kieren, 1995, p. 8).

I call this the relational dimension of mathematical activity,

Something in which we recognize,

And act on, the observation that

"We have only the world that we bring forth with others"

(Maturana \& Varela, 1998, p. 246).

\section{Speaking Up}

Is it only a matter of personal choice

To place at the center of my interest, as a mathematics educator,

Relationality

And the lived life of mathematical activity?

It is one thing to point to what we might miss,

With a model, or a theory.

Another one to realize what we get in return,

And reflect on why we do this.

Creating models and theories is also promoting a certain worldview.

Like here, by referring to mathematics knowledge, 
As if it existed in the form of a finite network, (even though not fully describable), (p. 11).

What ever we do always enlarges the space of the possible,

And raises the questions: What space? What possible?

I am not saying here that the Mowat and Davis model

Cannot have interesting educational implications.

But that this interest, for me, is not to be sought

In the possibility of guiding mathematics education.

Rather: in bringing about conversations

Conversations between researchers and teachers and students.

And all those in the school and the community

Who want to take a look into the learning of mathematics.

What Davis himself is still advocating for,

When he just recently writes

Concerning new understandings in mathematics education:

I am convinced that the critical element [...] is not a matter of finding ways to introduce [these new insights to teachers], but of finding ways to involve the teachers in the elaboration of the ideas (Davis, 2009, p. 272).

Again knitting,

Again promoting complicity,

Rather than producing knowledge,

To be imposed on the teachers.

We can do this.

It is up to us to make (mathematics) education,

What ever we want it to be.

Not to say that it is all easy,

Not to say that change will occur over night.

But if system there is -an educational system-

It exists only in and through our actions, all our actions.

Our action as connections,

As the linking from human to human.

In an through which culture, society, mathematics, education,

All these things,

Are produced and reproduced, day after day,

By you, by me, by all of us.

Change in education starts and ends by changes in what we do together.

How we do it, and why,

Entirely depends on the change that each and everyone of us is ready to make,

Here and now. 
Is it only a matter of personal choice

To place, over and over again,

Relationality at the center?

I think not!

I think it is an ethical choice.

For ethics precisely concerns this relationality

That permeates each and every one of our actions.

Like creating models, like writing papers:

Every human act has an ethical meaning, because it is an act of constitution of the human world. This linkage of human to human is, in the final analysis, the groundwork of all ethics as a reflection of the legitimacy of the presence of the others." (Maturana \& Varela, 1998, p. 247)

From an enactivist perspective, We need to bring back this relationality, At the center of our lives.

And not only need, but can, Knowing that "the world will be different only if we live differently" (p. 245).

\section{References}

Davis, B. (1995). Why teach mathematics? Mathematics education and enactivist theory. FLM, 15(2): 29.

Davis, B. (2009). And so...? In Mathematical representation at the interface of body and culture, edited by W.M. Roth, 257-273. Charlotte, N.C.: Information Age Publishing.

Haskell, J., Linds, W., \& Ippolito, J. (2002). Opening spaces of possibility: The enactive as a qualitative research approach. Forum: Qualitative social research, 3(3). Retrieved on November 21, 2009 from http://nbn-resolving.de/urn:nbn:de:0114-fqs0203145.

Kieren, T. (1995). Teaching mathematics (in-the-middle): Enactivist view on teaching and learning mathematics. Invited plenary lecture at the Queen's/Gage Canadian Mathematics National Leadership conference for teachers, Queens University. Retrieved on November 21, 2009 from http://www.ioncmaste.ca/homepage/discussion papers/Kieren,\%201995.pdf.

Lakoff and Núñez (2000). Where mathematics comes from. New York: Basic Books.

Maturana, H. R., \& Varela, F. J. (1998). The tree of knowledge (Revised ed.). Boston \& London: Shambhala.

Reiss, T. (1982). The discourse of modernism. New York: Cornell University Press. 


\section{About the Author}

Jean-François Maheux is currently a graduate student in the education faculty of the University of Victoria, and member of the CHAT@Uvic research lab. His research interests in theories of the act and enactivism lead him to study ethics in the day-to-day of researching, teaching and learning in mathematics education. Email at Maheux]f@Uvic.ca

(C) Copyright 2010. The author, JEAN-FRANCOIS MAHEUX, assigns to the University of Alberta and other educational and nonprofit institutions a non-exclusive license to use this document for personal use and in courses of instruction provided that the article is used in full and this copyright statement is reproduced. The author also grants a non-exclusive license to the University of Alberta to publish this document in full on the World Wide Web, and for the document to be published on mirrors on the World Wide Web. Any other usage is prohibited without the express permission of the authors. 